\title{
A IMPORTÂNCIA DA AULA DE CAMPO PARA A APRENDIZAGEM DO GRADUANDO EM CIÊNCIAS BIOLÓGICAS: ARMADILHA LUMINOSA (MARIPOSAS) NO POVOADO SANTA TERESINHA, TERESINA, PIAUÍ
}

\section{THE IMPORTANCE OF THE FIELD CLASS FOR THE LEARNING OF THE GRADUATE IN BIOLOGICAL SCIENCES: LUMINOUS TRAP (BUTTERFLIES) IN THE POVOADO SANTA TERESINHA, TERESINA, PIAUÍ}

\author{
Ester Veras Oliveira ${ }^{1}$; João Pedro Cardoso de Macedo²; Ana Victória Carneiro de \\ Araújo $^{3}$; Maria Edileide Alencar Oliveira ${ }^{4}$
}

\section{INTRODUÇÃO}

O processo de ensino-aprendizagem é bilateral, coletivo e dinâmico, assim, é importante que seja estabelecido parcerias entre alunos e professores, e entre os alunos coletivamente. Existem diversas estratégias no ensino de biologia que proporcionam o diálogo em sala de aula, entre elas pode-se destacar o estudo do meio, conhecido também como aula de campo (BRASIL, 2006). Com base nessa estratégia, este relato mostra uma aula de campo que aconteceu em um Povoado (Santa Teresinha), na cidade de Teresina, Piauí. Durante o primeiro semestre (2018.1) alguns alunos do Instituto Federal do Piauí (IFPI)/Campus Teresina Central foram instigados a vivenciarem outro modo de aprendizagem além da sala de aula, com o intuito de ajudar na sua futura vida acadêmica.

\section{RELATO DE EXPERIÊNCIA}

Embora escolas e laboratórios ainda sejam os locais onde acontece a maioria das atividades no curso de Ciências Biológicas, este não alcançará suas metas plenamente apenas nesses espaços curriculares (KRASILCHIK, 2004). A autora afirma que é preciso que também seja incluído atividades fora da instituição, para que haja contato direto com a realidade, para quando um licenciando se deparar com a sala de aula, possa ter experiências que levará a mediar os conhecimentos de maneira mais eficaz para seus alunos. Com esse intuito, alguns alunos do curso de licenciatura em Ciências Biológicas (Módulo III), do Instituto Federal do Piauí (IFPI)/Campus Teresina Central participaram de uma aula em campo que durou uma noite inteira (19 h às 7 h, dos dias 02 e 03 de agosto do corrente ano) com intenção de vivenciar a diversidade de insetos noturnos, principalmente, mariposas (armadilha luminosa), para que se aprendesse a instalação da armadilha, a captura dos insetos, e por fim, o processamento e armazenamento dos exemplares (insetos) a cada hora de trabalho. Nessa noite foram compartilhados ensinamentos que somente em sala de aula não seriam possíveis, pois foi necessária a demonstração de tudo, desde a captura de insetos até sua identificação, e cada 
momento vivido naquela noite serviu necessariamente para os estudos que estavam sendo ministrados em sala de aula, e que, em seguida seriam avaliados. Dessa forma, os alunos que participaram dessa experiência relataram suas opiniões de como essa aula influenciou em seu aprendizado como futuro professor: "A aula de campo me proporcionou uma visão mais ampla de conteúdo visto em sala de aula. É muito mais significativo quando você liga teoria com a prática. Certamente essa aula de campo me deu novas perspectivas quanto a ecologia. " (João Pedro Cardoso de Macedo).

“A aula de campo realizada foi de grande relevância para minha formação, visto que me deixou ainda mais interessada pelo curso que escolhi e abriu meu entendimento em relação a real importância da pesquisa. Além de ter inspirado muitos colegas que já estavam um pouco desanimados no curso.” (Andressa de Oliveira da Costa).

"Essa aula foi de grande importância, pois contribuiu muito para o meu entendimento em relação às mariposas. Ter contato direto com o que se trabalha, faz você perceber coisas que vão além da teoria." (Larisse dos Santos Fernandes).

\begin{abstract}
"Na referida aula de campo tive a oportunidade de por em prática alguns conceitos vistos em sala, com isso torna mais ampla minha aprendizagem e principalmente visualizar coisas até então vistas somente em livros ou citadas em classe. Lembro de um momento marcante em que chegamos as margens de uma lagoa com vasta vegetação em volta e a professora foi apresentando indivíduos e as relações ecológicas existentes ali."(Carlos Eduardo Castro Ribeiro).
\end{abstract}

A partir desses depoimentos, é notória a importância da experiência vivenciada por cada aluno, e como essa aula refletiu tanto na vida acadêmica como na intenção de permanecer no curso. Isso mostra que o aprendizado vai além das salas de aulas, ele está em todos os lugares, basta querer explorá-los, e isso numa aula de campo é uma estratégia fundamental. As imagens a seguir retratam esse dia com detalhes (Imagem 1, 2 e 3):

Imagem 1: Armadilha luminosa instalada para atrair os insetos durante a noite no Povoado Santa Teresinha, Teresina, Piauí. Fonte: Própria (2018).

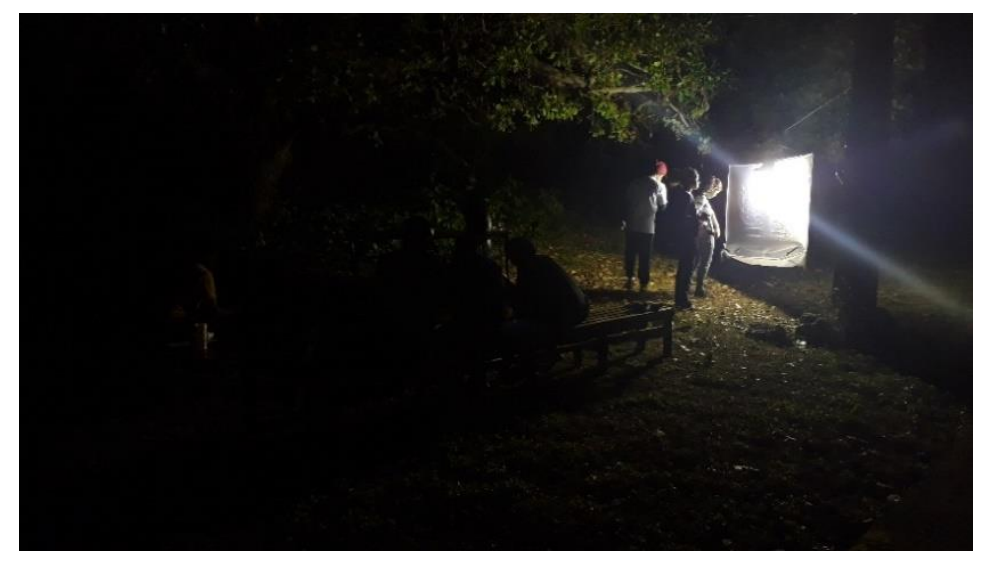


Imagem 2: Aula de campo no Povoado Santa Teresinha, Teresina, Piauí. Alunos processando insetos coletados na armadilha luminosa. Fonte: Própria (2018).

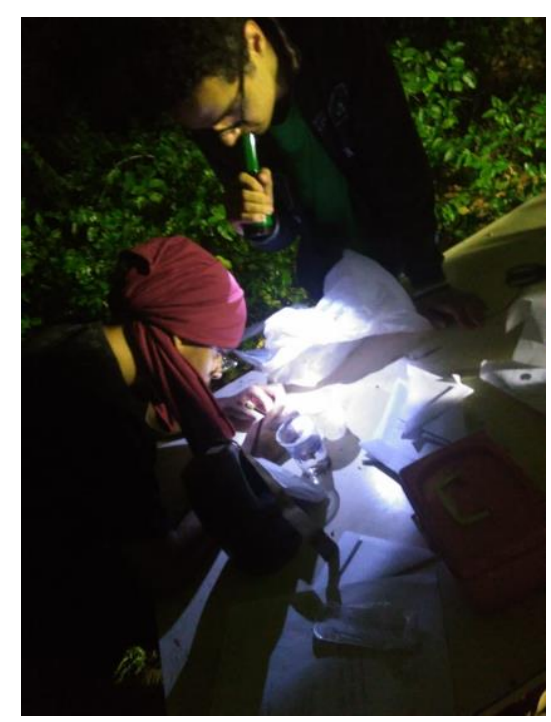

Imagem 3: No amanhecer do dia 03 de agosto de 2018, os alunos foram levados a conhecer um lago no Povoado Santa Teresinha, Teresina, Piauí. Fonte: Própria (2018).

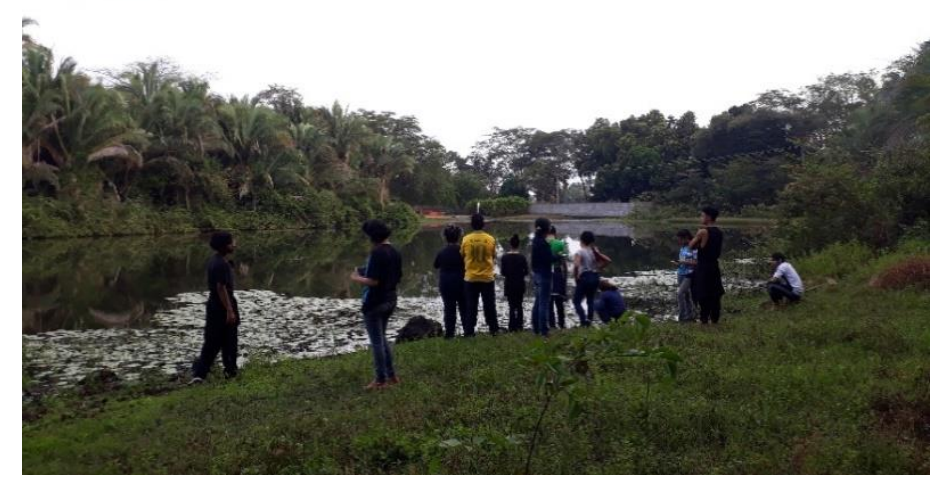

\section{CONSIDERAÇÕES FINAIS}

A aula de campo proporciona experiências que ultrapassam os saberes/conhecimentos desenvolvidos apenas em sala de aula. É um olhar mais ampliado do que já se aprendeu, é uma visão que não era compreendida apenas com as palavras do professor e do livro didático. Tal experiência que resultou em aprendizado que nunca mais será esquecido, e que influenciou até a nossa forma de ensinar para os futuros alunos, pois quando se muda um docente, também se muda a forma dele ensinar no futuro, o capacita para ser um profissional melhor, e isso torna a educação prazerosa, significativa e eficiente.

\section{REFERÊNCIAS}

BRASIL. Ministério da Educação. Secretaria de Educação Básica. Orientações curriculares para o ensino médio: ciências da natureza, matemática e suas tecnologias. Brasília: Ministério da Educação, Secretaria de Educação Básica, 2006. Disponível em: <http://portal.mec.gov.br/seb/arquivos/pdf/book_volume_02_internet.pdf>. Acesso em: 02 
OLIVEIRA, et. al

nov. 2018.

KRASILCHIK, M. Prática de ensino de biologia. 4. ed. rev e ampl. São Paulo: Editora da Universidade de São Paulo, 2004. 